\title{
O GOVERNO VARGAS E A COMISSÃO MISTA BRASIL-ESTADOS UNIDOS
}

\author{
Danilo José Dalio ${ }^{1}$ \\ Shiguenoli Miyamoto ${ }^{2}$
}

Resumo: O texto analisa as relações Brasil - Estados Unidos durante o segundo mandato de Getúlio Vargas, tomando como foco as negociações acerca da Comissão Mista criada pelos dois países. O Brasil adotou uma estratégia de barganha que acreditava factível naquele momento, qual seja: cooperação políticomilitar em troca de ajuda econômico-financeira e técnica. O resultado, embora frustrante para o governo Vargas, não obscurece a contribuição mais ampla dessa experiência de cooperação bilateral para o desenvolvimento econômico brasileiro. O fim da Comissão Mista evidenciou a assimetria de poder nas negociações entre os dois países, e as concepções divergentes sobre o desenvolvimento econômico para a América Latina.

Pavavras-chave: Comissão Mista Brasil , Estados Unidos, política externa brasileira, governo Vargas, desenvolvimento econômico.

Abstract:The paper analyses the relations between Brazil - United States during the second term of Getúlio Vargas, focusing on the negotiations about Joint Committee established by the two countries. Brazil adopted a bargaining strategy that he believed feasible at that time, namely, political-military cooperation in exchange for economic aid and financial and technical. The result, while frustrating for the Vargas government, does not obscure the broader contribution of this experience of bilateral cooperation for the Brazilian economy. The end of the Committee highlighted the asymmetry of power in negotiations between the two countries, and different ideas about economic development in Latin America.

Keywords: Joint Committee Brazil, United States, Brazilian foreign policy, Vargas government, economic development.

\footnotetext{
${ }^{1}$ Mestre em Ciência Política pela UNICAMP.

${ }^{2}$ Professor Titular do Departamento de Ciência Política do IFCH/UNICAMP.
} 
$|152|$

O governo Vargas e a comissão mista...

\section{Introdução}

O fim da Grande Guerra trouxe expectativas auspiciosas para a América Latina. Tratava-se de certo interesse demonstrado pelos Estados Unidos da América (EUA) para auxiliar a região. Obviamente havia contrapartidas. Enquanto o governo norte-americano empenhava-se na vertente estratégicomilitar, os latino-americanos queriam resolver seus problemas sócio-econômicos e estimular seu desenvolvimento. Foi neste contexto de definição de prioridades que se realizaram as negociações entre Brasil e EUA, visando ao incremento da cooperação econômica e militar. Iniciado no final do governo de Eurico Gaspar Dutra (31.01.46 a 31.01.1951), o diálogo assumiu caráter de urgência no começo de 1951, motivado pela Guerra da Coréia (25.06.50 a 27.07.1953), pelas demandas militares norte-americanas e pelas insistentes reivindicações brasileiras.

Entre a vitória eleitoral e a posse de Getúlio Vargas as negociações entre os dois países se intensificaram. Demandas de parte a parte foram apresentadas e discutidas. A promessa das autoridades norte-americanas, em julho de 1950, de conceder ao Brasil crédito junto ao Banco Internacional para a Reconstrução e o Desenvolvimento (BIRD) no valor de US\$ 250 milhões, com a esperança de mais US\$ 100 milhões do Export \& Import Bank (EXIMBANK), tomaria no início do segundo governo Vargas contornos mais precisos (Hilton, 1981: 606-08), exigindo em contrapartida uma definição mais aguerrida do governo brasileiro sobre sua participação no esforço político-militar norteamericano na Guerra Fria. Em fevereiro de 1951, o Secretário Adjunto para Assuntos Latino-Americanos, Edward Miller, veio ao Rio de Janeiro referendar às autoridades brasileiras a promessa de concessão de créditos e as expectativas de formação de uma

${ }^{3}$ Tratava-se de pôr em execução o famoso Ponto $I V$, anunciado no discurso de posse de Harry S. Truman em janeiro de 1949. Esse pronunciamento previa mais assistência técnica para o mundo inteiro, já que os EUA não dispunham de recursos para atender a demanda de cada país. Por isso, 
comissão técnica mista, feita ainda sob o governo Dutra ${ }^{3}$. Ao Brasil caberia, em retribuição, facilitar a remessa de minerais estratégicos para os Estados Unidos, ainda que desejasse a instalação no país das indústrias ligadas ao processamento de tais recursos (GV 51.02.19/1).

Os preparativos e a realização da IV Reunião de Consulta dos Chanceleres Americanos (Conferência de Washington em março/abril de 1951) favoreceram uma segunda rodada de negociações entre ambos. Falando em nome das nações do continente, a delegação diplomática brasileira argumentou a favor do caráter político do desenvolvimento da América Latina. Defendeu a necessidade de se desvincular os recursos para fins econômicos dos militares, a fim de que os primeiros não fossem preteridos em nome destes últimos (GV 51.03.16/1). Paralelamente ao enclave multilateral, a diplomacia brasileira privilegiaria as negociações bilaterais, solicitando junto aos EUA a ampliação da ajuda na área econômico-financeira, em troca do apoio dado para o arranjo da segurança continental, incluindo o fornecimento de matérias-primas estratégicas e a preparação militar doméstica. No balanço dos resultados angariados pelo Brasil, destacam-se a ampliação do crédito inicial para US\$ 300 milhões de dólares e a constituição de uma Comissão Mista integrada por técnicos brasileiros e americanos, conforme já previsto, para estudar planos básicos ao desenvolvimento brasileiro (GV 51.01.04/2 e GV 51.04.05/2).

A Comissão Mista Brasil - Estados Unidos para o Desenvolvimento Econômico (doravante CMBEU), uma das promessas de Harry S. Truman para as economias periféricas,

apostaram no envio de especialistas que fornecessem um diagnóstico para investimentos privados. Todavia, o Ponto IV não alterou nem ampliou a ajuda americana para as economias menos desenvolvidas. Ainda assim, essa notícia sobre um programa de auxílio técnico provocou expectativas otimistas nos países possivelmente contemplados. Também conhecido como Lei do Desenvolvimento Internacional, o Ponto IV permitiu que oito países incluindo o Brasil adotassem a idéia (CAMPOS, 1994: 155). 
|154|

O governo Vargas e a comissão mista...

criada em 19 de julho de 1951 no segundo governo de Getúlio Vargas (31.01.51 a 24.08.54) resultou desse esforço diplomático anterior.

A seção brasileira da CMBEU foi presidida pelo engenheiro gaúcho Ary Frederico Torres - conforme nomeação do Ministro da Fazenda Horácio Lafer -, assessorado por quatro conselheiros técnicos e um econômico. Dentre os técnicos estavam o geólogo Glycon de Paiva Teixeira, ex-diretor do Departamento Nacional de Produção Mineral (criado em 1934); Lucas Lopes, um dos fundadores da Companhia Energética de Minas Gerais S/A (CEMIG); o conselheiro financeiro era Victor Bouças, presidente do Conselho Técnico de Economia e Finanças; o secretário-executivo era Vitor da Silva Alves, ex-funcionário das Nações Unidas e que viria a ser diretor do BIRD; e como conselheiro econômico atuou o diplomata e economista Roberto de Oliveira Campos (Campos, 1994:159).

A seção norte-americana, por sua vez, ficou sob o comando do embaixador americano Merwin Bohan, substituto de Francis Trulow, corretor da Bolsa de Nova York, falecido em viagem ao Rio de Janeiro quando assumiria o cargo. Em outubro de 1951, Bohan fora substituído pelo economista do Banco Mundial, J. Burke Knapp, que permaneceria no cargo até agosto de 1952.

Desde o início o governo brasileiro definiu as prioridades que orientariam os rumos da CMBEU. A base para nortear os trabalhos conjuntos foi o relatório ABBINK divulgado em junho de 1949, produzido para identificar os "nós" que emperravam o desenvolvimento 4 . De acordo com Octávio Gouveia de Bulhões e Eugênio Gudin, que coordenaram tal relatório, os setores com probabilidades maiores de efeito multiplicador do crescimento sustentado eram: transportes (ferrovias), energia elétrica, modernização dos portos e agricultura (construção de armazéns).

${ }^{4}$ O Relatório Abbink foi uma das etapas de cooperação econômica entre Brasil e EUA. Ver: http://www.cpdoc.fgv.br/dhbb/verbetes_htm/1790_17.asp. Acesso em 20 de março de 2009. 
O objetivo da CMBEU era "[...] promover o desenvolvimento econômico, tendo em vista, particularmente, a formulação de planos de investimento destinados a vencer as deficiências em transporte e energia [...]" (CMBEU, Relatório Geral, Tomo I, 1954: 11), vale dizer, criar condições favoráveis e eliminar obstáculos para estimular os investimentos privados nacionais e estrangeiros. Não havia interesse na elaboração de um plano amplo de desenvolvimento nem uma política de industrialização, mas sim fomentar oportunidades para o empresariado (Viana, 1980:109) ${ }^{5}$. Cumpria-se, portanto, uma visão de planejamento seccional, apoiada pelos membros da seção técnica brasileira (dentre eles Roberto de Oliveira Campos), que consistia em estabelecer políticas para setores específicos, por isso de mais fácil execução, considerados "pontos de estrangulamento" na economia brasileira, a exigir o mínimo de intervenção estatal (Bielschowsky, 1996:112).

\section{O acirramento das negociações}

Aos dois momentos anteriores à CMBEU veio se somar uma terceira rodada ocorrida em Washington em setembro de 1951. Nesta oportunidade, o Ministro da Fazenda Horácio Lafer e Eugênio Gudin se encontraram com o general Aurélio Góes Monteiro, que fora negociar o lado militar da cooperação, embora não dispusesse de instruções específicas sobre a $\mathrm{CMBEU}^{6}$.

${ }^{5}$ A Comissão Mista propunha apenas a reaparelhar a infra-estrutura econômica do país, ou seja, eliminar os pontos de estrangulamento em transporte e energia. No Relatório Geral dizia: “A Comissão Mista não foi concebida como um órgão geral de planejamento, nem se propôs a assim agir. Além disso, não procurou de forma alguma substituir por um programa governamental os planos de investimento porventura feitos pelo setor privado da economia. Muito ao contrário, esforçou-se por planejar e estimular medidas que criassem condições prévias favoráveis a um maior surto de iniciativa privada". (Apud Viana, 1980: 109).

${ }^{6}$ Nos dois primeiros momentos definiram-se os aspectos mais gerais das negociações, como os termos-base de cooperação entre os dois países 
O governo Vargas e a comissão mista...

Com o objetivo de assistir às reuniões do Banco Mundial (BIRD) e do Fundo Monetário Internacional (FMI), respectivamente, a viagem de Lafer e Gudin foi cercada de expectativas. Ambos eram vistos com simpatia pelo governo norte-americano, por representarem uma continuidade promissora em torno dos debates sobre as questões financeiras. O general Góes Monteiro limitou-se a enfatizar a importância que o Brasil atribuía à CMBEU (GV 51.09.04/3). Conforme relatou Valentim Bouças a Vargas, a boa acolhida recebida pela Missão Lafer, era um sinal de "como os nossos amigos americanos estão a favor de sua administração" (GV 51.09.12/1).

Nesse ambiente favorável à política econômica brasileira (cortes de despesas e busca de equilíbrio orçamentário), o Ministro da Fazenda esperava contar com a ajuda de membros da administração Truman, dentre eles a do Secretário do Tesouro John W. Snyder "considerado em Washington como o maior opositor a empréstimos para outros países", do presidente do Federal Reserve Bank William McChesney Martin Jr., e do Secretário Adjunto para Assuntos Latino-americanos Edward Miller (GV 51.09.12/1). O otimismo brasileiro tinha suas razões: em uma das assembléias do BIRD e do FMI, Lafer fora escolhido presidente do Conselho de Governadores da primeira instituição, e Gudin presidente do Conselho da segunda. Nesse encontro, considerado o mais importante entre todos, o Secretário do Tesouro, os presidentes do BIRD Eugene Black, do EXIMBANK Herbert Gaston, e o Secretário Adjunto Edward Miller assinaram com Lafer, um memorando realçando a importância do programa e dispondo-se a fornecer os recursos necessários para os projetos estudados e recomendados pela CMBEU. (Weiss, 1986/2: 65)

Este documento foi um grande avanço se comparado aos acordos de março/abril de 1951, porque não previa restrições frentede pagamentos" (CMBEU, 1954), já que parte

(GV 51.01.04/2) e os valores absolutos de financiamento externo (GV 51.03.16/1). 
do financiamento dos projetos elaborados pela Comissão viria da captação de a possíveis "mudanças imprevisíveis na posição da balança recursos internos. Animado pelos resultados de tal acordo, pela receptividade, e com o apoio do Secretário do Tesouro, Lafer pretendia expandir o limite de crédito obtido de US\$ 300 para US\$ 500 milhões, reservando US\$ 100 milhões para obras urgentes de portos e estradas de ferro. (GV 51.09.12/1), o que de fato não ocorreu senão apenas como possibilidade a analisar. Os acordos firmados pelo ministro Lafer com o BIRD converteram-se em motivo de regozijo para si mesmo, porque ele havia assumido a responsabilidade pelas medidas fiscais consideradas necessárias, porém impopulares, para financiar a porção do programa em cruzeiros. Por isso, era importante o compromisso formal de que o capital estrangeiro realmente viria. $^{7}$

Os resultados obtidos por Lafer e Gudin aparentemente sinalizavam de forma positiva para uma aproximação maior nas áreas de segurança e cooperação militar entre Brasil e EUA, até então relegadas a segundo plano. Atendidos os objetivos financeiros pareceu "oportuno afrouxar um pouco, fazendo concessões", pois a continuação dos trabalhos seguiria em "magnífico ambiente", acreditava o Ministro Fontoura (GV 51.09.12/1). ${ }^{8}$

Para oficializar o apoio e a contrapartida no financiamento dos projetos sugeridos pela CMBEU, o Ministro da Fazenda

\footnotetext{
${ }^{7}$ Em novembro de 1951, Lafer comunicou a Vargas a aprovação do Senado autorizando o Executivo a dar garantia de até US\$ 750 milhões dos créditos que fossem obtidos no exterior. GV 51.11.00, Carta de Horácio Lafer a Getúlio Vargas (nov./51). (Cruz, 1983: 89).

${ }^{8}$ Apesar disso, as negociações acerca dos compromissos militar-estratégicos (Acordo Militar e venda de manganês, urânio e areias monazíticas) não caminharam a contento; as decisões tiveram de esperar o ano seguinte e ser discutidas no Rio de Janeiro, pelo chanceler e pelo Embaixador Herschel V. Johnson (GV 51.10.03/5).
} 
$|158|$

O governo Vargas e a comissão mista...

anunciou em setembro de 1951 um plano qüinqüenal centrando os investimentos em indústrias de base, energia e transportes. O Plano Nacional de Reaparelhamento Econômico (Plano Lafer) criava o Fundo de Reaparelhamento Econômico, uma fonte especial para alocar o aumento de $15 \%$ no imposto de renda. Em 5 de dezembro de 1951, o Congresso Nacional aprovou o aumento do imposto e o plano, que racionalizava os investimentos em projetos de desenvolvimento econômico. Com essa iniciativa o governo Vargas implementou uma linha de investimento à base de capitais nacionais e estrangeiros, sob coordenação do Estado (D'Araújo, 1992: 165). ${ }^{9}$

$\mathrm{O}$ ano de 1951 encerrou-se com um balanço promissor em termos de cooperação, com a CMBEU funcionando integralmente e preparando projetos e estudos técnicos. Apesar da resistência em atender ao pedido norte-americano para participar ativamente da Guerra da Coréia, o saldo também foi positivo para os EUA, uma vez que o arrefecimento do conflito asiático garantiu um contentamento mútuo com a colaboração indireta do Brasil por meio do fornecimento de minerais estratégicos e do avanço nas negociações acerca do Acordo Militar.

\section{Demandas, expectativas e desconfianças}

Se as relações bilaterais passaram por momento favorável em 1951, o mesmo não se verificou no ano seguinte, quando um clima de desconfiança pairou entre os dois países. Uma sucessão de acontecimentos neutralizaria as conquistas anteriores.

Ainda em dezembro de 1951, Vargas enviou um projeto de lei ao Congresso Nacional propondo a criação da Petrobrás, como

\footnotetext{
${ }_{9}^{9}$ Para Ianni, o Plano Nacional de Reaparelhamento Econômico, além de oficializar os projetos da Comissão Mista, significou a conciliação entre a decisão dos governantes impulsionarem o desenvolvimento econômico brasileiro, a escassez de recursos (capital e tecnologia) nacionais e a nova fase de expansionismo econômico dos Estados Unidos (Ianni, 1971: 117).
} 
empresa mista (público-privada) e com o controle majoritário nas mãos do governo. (Vargas, 1969: 75-97) No Departamento de Estado a reação não foi de total repulsa. Embora fossem contrários a empresas estatais e à exclusão do capital estrangeiro (não considerada inicialmente), os EUA acreditavam que o Congresso brasileiro poderia introduzir alterações no projeto original (Weiss, 1986/2: 66). À medida que o projeto da Petrobrás tramitava no Congresso e ganhava contornos cada vez mais monopolistas e nacionalistas, arregimentando apoio popular, a oposição americana recrudescia, resgatando a intensa controvérsia dos anos 40 (GV 51.09.02/1). Durante os dois anos seguintes, até a aprovação da Petrobrás, os debates sobre a política petrolífera abrangeram não apenas as relações bilaterais, mas também o próprio caráter do desenvolvimento brasileiro (Cohn, 1968).

Outro fator que contribuiu para desestabilizar as relações bilaterais foi o pronunciamento de Vargas, em rede nacional de rádio em 31 de dezembro de 1951. Na oportunidade, criticou duramente as empresas estrangeiras por "sangrarem" o Brasil com vultosas remessas de lucros e juros para o exterior, que passaram de US\$ 83 milhões em 1950 para US\$ 137 milhões em 1951 (Vargas, 1954: 65-77).

Isto descumpria o estabelecido pelo artigo $6^{0}$ do DecretoLei 9.025 de 27 de fevereiro de 1946, quando se estipulou um teto para operações dessa natureza: "as remessas de juros, lucros e dividendos não ultrapassarão $8 \%$ do valor do capital registrado, considerando-se transferência de capital o que exceder a essa percentagem". O desrespeito a essa norma levou Vargas a baixar o Decreto-Lei 30.363 em 3 janeiro de 1952, determinando que o capital estrangeiro com direito a retorno era apenas $8 \%$ do valor original efetivamente ingressado no país, e que constasse no registro da Carteira de Câmbio do Banco do Brasil. O decreto garantia à Superintendência da Moeda e do Crédito (SUMOC), o poder de aplicar esses limites em épocas de pressão sobre a balança de pagamentos. Essa medida teve duplo impacto: de um lado acirrou o descontentamento por parte dos EUA, mas em 
$|160|$

O governo Vargas e a comissão mista...

contrapartida o prestígio de Vargas ficou fortalecido junto aos setores nacionalistas e de esquerda no Brasil (GV 52.01.18).

A iniciativa de Vargas mobilizou as instâncias comprometidas com as negociações americano-brasileiras, particularmente com os trabalhos da CMBEU.

Dias depois do decreto, João Neves da Fontoura encontrou-se com o embaixador Herschel Johnson e tentou minimizar o impacto do conteúdo xenófobo que o novo regulamento deixava visível. Artífice das boas relações com o governo americano, Neves da Fontoura ("antes do Plano Lafer existia o Plano Neves", ele dizia) julgava ameaçadora a repercussão do decreto sobre os compromissos assumidos com a CMBEU, e sugeriu uma interpretação jurídica do DL 9.025, afirmando que o DL 30.363 representava apenas uma adequação da norma já existente.

Arriscando-se a perder os recursos prometidos pelo BIRD até o final de julho de 1952, o Brasil poderia implodir seu plano financeiro, necessitando recorrer à emissão e à inflação, medida cujas conseqüências seriam imprevisíveis "no plano interno e internacional em face do comunismo". Segundo o Ministro das Relações Exteriores, era necessário também impedir a divulgação da entrevista do presidente do Banco do Brasil, Ricardo Jafet. Para manter o bom relacionamento com o capital estrangeiro, ademais, outras arestas deveriam ser aparadas com a instituição do mercado livre de câmbio. Não se tratava de uma retratação, mas de esclarecer os inconvenientes e as desconfianças para quem quisesse investir no Brasil (GV 52.01.31/4). ${ }^{10}$

Apesar do desconforto, as relações bilaterais e o futuro da CMBEU continuaram a ser objeto de negociações. Vargas fez notar

\footnotetext{
${ }^{10} \mathrm{Na}$ entrevista citada, Jafet diz: “ $\mathrm{E}$, evidentemente, o Brasil não poderia constituir-se em protetor incondicional de uma situação monopolística de antigas inversões estrangeiras diante da barreira que se erguia impedindo a entrada de novos capitais". A prevenção de Neves devia-se ao fato de Jafet procurar justificar o Decreto-Lei 30.393 de 3/01/52 com o mesmo tom de Vargas em 31/01/51, isto é, atacando.
} 
a Herschel Johnson e a Merwin Bohan sua insatisfação com o lento desdobramento da CMBEU, quando se encontraram em maio de 1952.

Naquela altura, a CMBEU já tinha enviado ao Departamento de Estado 15 projetos que aguardavam financiamento. Ao mesmo tempo o governo brasileiro criou o Banco Nacional de Desenvolvimento Econômico (BNDE), que administraria os recursos obtidos junto ao BIRD e ao EXIMBANK, bem como os fundos do Plano Lafer (Vargas, 1969: 98-121). O BNDE surgia como órgão mediador entre o Estado, o setor privado nacional e as agências internacionais, o tripé do projeto de desenvolvimento varguista (Hirst, 1990: 17). Em junho de 1953 o Banco iniciou suas atividades, incorporando aos seus quadros vários membros da CMBEU.

Contudo, mostras de boa vontade não foram suficientes para neutralizar a animosidade do Departamento de Estado e das instituições comprometidas com a CMBEU. João Neves da Fontoura e Horácio Lafer inclusive apoiaram um projeto de lei do deputado Adolpho Gentil (PSD-Ceará) que propunha dividir o mercado de câmbio em uma taxa oficial para transações de capital, e uma cotação livre para o comércio normal.

Dificuldades técnicas para viabilizar o DL 30.363, e apreensões do mercado internacional, fizeram com que as limitações existentes fossem abolidas um ano depois. Criou-se em janeiro de 1953 o mercado livre de câmbio, que vigorou até outubro de 1953, substituído pela Instrução 70 da SUMOC. Além da proposta do mercado livre de câmbio, o embaixador Maurício Nabuco foi substituído por Walter Moreira Salles, amigo de Fontoura e banqueiro de confiança do Departamento de Estado (GV 52.04.04/1).

A demora na liberação dos financiamentos aos projetos "pendentes" gerava impaciência entre os ministros brasileiros. Edward Miller e Merwin Bohan, aparentes aliados do governo brasileiro, procuraram convencer o BIRD e o EXIMBANK a elaborar um pacote de empréstimos no valor de US\$120 milhões, 
$|162|$

O governo Vargas e a comissão mista...

inclusive porque havia uma viagem programada do Secretário de Estado Dean Acheson ao Brasil, no início de julho.

Ciente dessas conversações, Getúlio Vargas enviou Valentim Bouças aos EUA para negociar com as duas instituições. Daí resultou a aprovação pelo EXIMBANK de US\$ 60 milhões para três projetos: Companhia de Estradas de Ferro; Estrada de Ferro Santos - Jundiaí; e Brazilian Eletric Power Company, subsidiária da American Foreign Power Co. Por sua vez, o BIRD condicionara seus financiamentos à aprovação pelo Congresso brasileiro da lei do mercado livre. Menos de seis meses depois de garantir seu apoio a Lafer, Eugene Black disponibilizou apenas US\$ 40 milhões, muito aquém do esperado. Irritou-se também Valentim Bouças ao ouvir de Black a exigência de que deveria ser consultado previamente, caso o governo brasileiro entrasse em negociações com bancos privados para quitar dívidas atrasadas. Em carta a Vargas, aconselhava-o a apoiar publicamente a lei do mercado livre de câmbio a fim de não prejudicar o andamento da CMBEU e outros projetos como o da Petrobrás. (GV 52.05.26)

De férias, o Secretário de Estado Dean Acheson visitou o Brasil em dois de julho, quando aproveitou para diminuir os atritos em assuntos que dificultavam as relações entre os dois países. Dentre esses, recursos para os projetos da CMBEU, ampliação da assistência técnica, compra e arrendamento de navios mercantes (GV 52.06.16/2). Os métodos de Acheson já eram conhecidos: ênfase na reciprocidade da CMBEU e nos resultados práticos do planejamento, julgando os êxitos não apenas pelo conjunto dos recursos mas pelo legado deixado ao desenvolvimento brasileiro. Até aquele momento, o EXIMBANK e o BIRD haviam anunciado seis acordos no valor de US\$100 milhões, quantia inferior à que o governo esperava contar.

A reunião entre o Secretário de Estado, o presidente Vargas e os ministros Fontoura e Lafer foi marcada por demandas distintas. Para os EUA, o foco estava na falta de apoio brasileiro à Guerra da Coréia e no decreto sobre a remessa de lucros; ao Brasil interessava o preço do café e o atraso na liberação dos recursos aos projetos já aprovados. No discurso de abertura do 
encontro, o Ministro Fontoura enfatizou a amizade histórica entre Brasil e EUA, porém reivindicou maior aprofundamento da cooperação no campo econômico e financeiro em conformidade com o Ponto IV e a CMBEU. (GV 52.06.16/2)

Apesar do tom cordial, a administração Truman evitava comprometer o próximo governo, já que havia indícios de que nas eleições de novembro a vitória caberia ao Partido Republicano. Não obstante a generalidade da agenda, a viagem de Acheson se constituiu no "ponto alto do êxito da CMBEU e das relações Brasil-EUA", sob o governo Vargas (Weiss, 1986/2: 68). No dia seguinte àquele encontro, o Brasil comemorou o empréstimo de US\$ 94,5 milhões dos quais US\$ 57 milhões pelo EXIMBANK e US\$ 37,5 milhões pelo BIRD, sendo 30\% reservados à reabilitação da malha ferroviária e o restante para a expansão de instalações geradoras de energia elétrica. (GV 52.07.03)

Para o governo norte-americano e as instituições financeiras, todavia, o problema com o Brasil estava na falta de uma lei favorável ao livre comércio e nas restrições do balanço de pagamentos brasileiro. A viabilidade técnica dos projetos da CMBEU deveria ser, portanto, uma preocupação secundária. Essa orientação era agravada pela proximidade das eleições presidenciais de novembro de 1952.

Nos últimos três meses que antecederam o pleito, o EXIMBANK autorizou somente três novos empréstimos ao Brasil: um de US $\$ 67,5$ milhões para uma empresa mista brasileiro-americana explorar manganês no Amapá; outro de US\$ 18 milhões ao BNDE para a compra de equipamentos agrícolas para revenda; e um de US\$1,86 milhões à Companhia Metalúrgica Bárbara para a expansão de sua indústria de ferro fundido. Esses recursos só foram obtidos por causa da firme intervenção do Departamento de Estado e do presidente do EXIMBANK junto ao BIRD e a Comissão de Valores \& Câmbio dos EUA, para os quais a solução do balanço de pagamentos e o mercado livre de câmbio eram condições fundamentais para a liberação dos créditos. (Weiss, 1986/2: 69) 
|164|

O governo Vargas e a comissão mista...

Para o Brasil colocava-se a urgência na aprovação dos projetos da CMBEU e a liberação dos empréstimos antes do fim da administração democrata. Como previsto, a vitória dos republicanos representou o início de um governo pouco afeito às demandas das economias periféricas. (GV 51.05.24 e GV 51.09.04/3)

Em setembro de 1952, Horácio Lafer participou da $7^{\text {a }}$ Reunião dos Governadores do BIRD e do FMI realizada em Washington. Na ocasião, o ministro estabeleceu contatos com países europeus, para discutir empréstimos, e mostrou-se mais uma vez otimista com a visão que as "autoridades técnicas e políticas das finanças" possuíam do problema dos atrasados comerciais e do desequilíbrio da balança de pagamentos. (GV 52.09.15/3)

No mês seguinte as arremetidas sobre os EUA e setores financeiros se intensificaram. $O$ discurso proferido pelo embaixador Moreira Salles no dia 7 de outubro em Nova York, no almoço da "American Brazilian Association", mostrou o tom realista da "linha de nossa política econômica em relação à América". Enfatizando a solidariedade e a colaboração nacional para com os EUA, o embaixador questionou: "como seria possível deixar de reconhecer que o desenvolvimento econômico do Brasil é a chave da defesa do continente latino-americano?". (GV 52.10.10/1)

A vitória de Dwight D. Eisenhower sobre Adlai Stevenson, em novembro, acelerou o curso de ação da diplomacia econômica brasileira (GV 52.09.23). Em viagem para participar da Assembléia Anual das Nações Unidas, João Neves da Fontoura ouviu de Acheson a garantia "de que nenhuma mudança substancial haverá na política externa dos EUA, sobretudo no tocante ao Brasil". Apesar de também receber de Rockefeller e Eisenhower a promessa de continuidade da cooperação com o Brasil, Fontoura prenunciava as dificuldades que o presidente norte-americano enfrentaria no setor externo, em face do "fundo isolacionista" de seu partido. E advertia a Vargas: "Nosso papel, sobretudo 
o seu, tem de ser muito vivo para arrancarmos tudo quanto seja indispensável ao nosso país". (GV 52.11.10/1)

Oswaldo Aranha, ex-ministro de Vargas e homem de confiança nos círculos financeiros internacionais, também foi aos EUA (OA 52.12.08). Para ele as conversações mantidas por Neves da Fontoura tinham sido puramente formais e julgava prioritária a liquidação dos atrasados comerciais brasileiros (OA 53.02.05). Em sua avaliação, seria um equívoco arrastar velhos problemas para a nova administração republicana, "justamente quando o interesse do Brasil assenta em contas novas, novos créditos e possibilidades novas para novas compras e empreendimentos".

Para tanto, a sugestão de Aranha era de que o EXIMBANK pagasse imediatamente os exportadores americanos, em dinheiro os pequenos e em títulos os demais, ou da maneira que quisessem, e recebessem do Banco do Brasil, títulos ou obrigações a vencerem num prazo de seis meses. Com os outros países, a situação dos atrasados comerciais seria liquidada através da compra das moedas necessárias junto ao FMI em condições de prazo e taxas favoráveis. (GV 52.12.02/4 e GV 52.12.04/3)

Até aquele momento, o diálogo sobre os atrasados comerciais brasileiros com os EUA, conforme instruções de Horácio Lafer, e sob responsabilidade do embaixador Moreira Salles, tinha levado às seguintes conclusões acertadas com o EXIMBANK e o BIRD: 1) o Brasil poderia dispor de US\$ 70 milhões do FMI para atender as exigências financeiras do comércio exterior; 2) negociou-se com o Fundo, uma operação de compra e venda de US\$ 18 milhões, pagáveis até 1954; com o EXIMBANK, um empréstimo de US\$ 250 milhões ao Banco do Brasil para quitar atrasados comerciais, amortizáveis em quatro anos a partir de 1955 , com juros de $3 \%$ e $5 \%$. A maior dificuldade encontrada pelo Brasil era fazer com que se aprovassem essas transações antes do início do governo Eisenhower. (GV 52.12.02/4)

Enquanto o debate no Congresso Nacional sobre a nova lei do mercado livre de câmbio claudicava, o governo procurou se adiantar nas negociações com as agências financeiras e com FMI. Para estes, empréstimos para saldar os atrasados comerciais 
|166 |

O governo Vargas e a comissão mista...

passavam necessariamente pela reforma na política cambial e financeira do Brasil. (GV 52.12.04/3; GV 52.12.19/3 e OA 52.12.00)

Contrariado com as instruções de Lafer que previam um empréstimo puro e simples de US\$200 a 250 milhões para liquidação dos atrasados, Oswaldo Aranha defendia sua própria proposta junto a Vargas. A preocupação de Aranha era fixar bases sólidas com a Casa Branca, deixando explícito em memorando as intenções de colaboração e reciprocidade do governo brasileiro (GV 52.12.04/3). No final de dezembro Eisenhower recebeu Aranha, propondo-lhe que se avistasse com o futuro Secretário de Estado, John Foster Dulles, e mostrou-se animado com a idéia de receber Alzira do Amaral Peixoto, filha do presidente, para uma conversa mais formal sobre o Brasil, conforme lhe sugerira o ministro.

Apesar da insistência brasileira na liberação dos créditos para os projetos da CMBEU, a lei de remessa de lucros de janeiro de 1952 e a demora na aprovação da lei do mercado livre de câmbio constituíram-se em obstáculos para agilizar as negociações com as agências financeiras, exasperando a desconfiança do Departamento de Estado, ainda sob a administração Truman.

O último empréstimo deste governo a projetos da CMBEU foi feito pelo EXIMBANK à Companhia Vale do Rio Doce S/A, no valor de US\$ 7,5 milhões, negociado entre o presidente da CVRD Juracy Magalhães, e o do Banco, Herbert Gaston. Durante todo o ano de 1952, os recursos da CMBEU limitaram-se a US\$ 81,6 milhões. Já o BIRD concedeu ao Brasil US\$ 37,5 milhões, todo direcionado aos projetos conjuntos da CMBEU. (Weiss, 1986/2: 70)

\section{A difícil conciliação: rumo ao fim}

As relações econômico-financeiras entre Brasil e EUA em 1953 enfrentaram múltiplas dificuldades. De um lado, o esmorecimento do apoio de Washington; de outro, a falta de definição das atribuições de cada instância financeira e de suas relações com o Departamento de Estado. 
Apesar de sinais favoráveis à continuidade da cooperação bilateral, eram patentes as diferenças entre os governos democrata e republicano. Enquanto a gestão de Truman era considerada flexível, o novo governo adotou uma estratégia de segurança a longo prazo sob a qual a ajuda externa estaria subordinada, ou seja, "high flexibility and modern genius vs. monolithic mass" (OA 53.02.03/1). Os mais otimistas acreditavam na possibilidade de compatibilizar a política externa brasileira e os objetivos econômicos pretendidos à dinâmica da administração Eisenhower, buscando atrair os capitais privados como base para financiar o projeto desenvolvimentista. (GV 53.01.21/2)

Os obstáculos imediatos residiam, sobretudo, na dificuldade para convencer as agências financeiras. Em meados de janeiro de 1953, Mervin Bohan encontrou-se com representantes do BIRD (Black, Garner, Knapp) para discutir a liberação dos empréstimos aos projetos ferroviários. Lembrou-lhes que os EUA e o BIRD tinham um compromisso implícito de financiar o programa, e que a promessa de colaborar com a CMBEU induzira Vargas a cooperar em outras questões. Eugene Black, por sua vez, afirmou que a instituição não tinha deveres para com o Brasil e que os membros europeus do Banco se opunham a novos empréstimos até que se resolvessem as dívidas atrasadas. Ainda deixou claro que o BIRD não comprometeria seus princípios para adequar-se à política dos EUA.

Vargas tomou algumas iniciativas: pressionou o chefe norte-americano da CMBEU e a aprovação de empréstimos adicionais. Em 31 de janeiro elogiou o trabalho da CMBEU por ter aprovado 23 projetos no valor de US\$ 264 milhões e Cr\$ 7,4 bilhões, quantia esta que poderia ser ampliada para US\$ 500 milhões e Cr\$ 15 bilhões.

Outra iniciativa do presidente brasileiro, aceitando conselho de Oswaldo Aranha, foi construir um relacionamento pessoal com Eisenhower. Assim, propôs enviar sua filha Alzira Vargas do Amaral Peixoto e o genro Ernani do Amaral Peixoto a Washington, em seu lugar. Ao responder, Eisenhower afirmou ser "a fine gesture of friendship between our two countries (...) 
$|168|$

O governo Vargas e a comissão mista...

serve to emphasize once more the firm and historic ties which have always existed between Brazil and the United States of America". (GV 53.02.02/1)

Informando o pai sobre o clima acolhedor encontrado na visita realizada ao final de abril, Alzira falou do receio do governo americano pela continuação indefinida dos estudos da CMBEU que em sua maioria não seriam financiados porque eram "inviáveis para nós e para eles, mantendo uma comissão que lhes custa muito caro". O governo republicano pretendia efetuar cortes orçamentários, e negava ter assumido o compromisso de financiar os projetos feitos pela CMBEU até certo limite. Vargas foi informado, ainda, que se desejasse, seria possível adiar por mais algum tempo o fim da CMBEU. (GV 53.02.02/1)

Enquanto Vargas tentava a diplomacia pessoal, dois problemas atuavam contra o futuro da CMBEU em Washington: o reaparecimento da crise do balanço de pagamentos brasileiro e a decisão de excluir o EXIMBANK das negociações.

Em fevereiro de 1953 a dívida do Brasil atingiu a cifra de US\$ 450 milhões e tanto os exportadores americanos quanto Oswaldo Aranha pressionavam o EXIMBANK a liberar um empréstimo de US\$ 300 milhões. Em setembro de 1952 as autoridades norte-americanas haviam imposto a Lafer, como condição para o Brasil receber empréstimo do EXIMBANK, a necessidade de se aprovar a lei do mercado livre de câmbio. Em janeiro de 1953, quando se suprimiram as exigências impostas pelo DL 30.363 e institui-se, em fevereiro seguinte, o mercado livre de câmbio, a exigência do BIRD passou a ser a quitação dos atrasados comerciais, alegando que o descumprimento dessa exigência colocaria em risco os projetos da CMBEU.

Durante as negociações para saldar os atrasados comerciais o governo Eisenhower decidiu excluir o EXIMBANK como fonte de empréstimo para o desenvolvimento, embora fosse essa sua função para facilitar o comércio. O Secretário do Tesouro George Humphrey entendia que as finanças americanas estavam sobrecarregadas para se permitir aplicações desnecessárias. O BIRD, agora opção única, impunha à sua lista de requisitos 
para futuros empréstimos a execução de uma política petrolífera liberal.

Apesar do esforço brasileiro para salvar o que restava da CMBEU, o contexto inaugurado pela administração Eisenhower conspirava contra as pretensões do governo Vargas. A fidelidade ao conservadorismo fiscal e a obcecada inclinação pela segurança internacional chocavam-se com os desígnios da CMBEU e à esperança de ajuda financeira complementar. Ao Secretário de Estado John Foster Dulles e seu adjunto para Assuntos Interamericanos John Moors Cabot, pouco interessavam as conseqüências do fim da CMBEU para a estabilidade do governo Vargas. Nem havia pretensões de investir na cooperação.

Assim, em abril de 1953, o embaixador Herschel Johnson sugeriu ao Ministro da Fazenda a extinção da CMBEU, cujos projetos seriam concluídos em 30 de junho do mesmo ano. Deixava, porém, a critério do Brasil a definição da data de encerramento. (GV 53.04.00/5) Por sua vez, as autoridades brasileiras solicitaram a Johnson que retardasse a entrega da nota sobre o fim da CMBEU, aguardando os resultados das conversações mantidas por Ary Torres nos EUA e a visita de Milton Eisenhower, irmão do presidente, em julho ao Brasil. $(\text { GV 53.04.16/2) })^{11}$

Naquela altura, o Ministro João Neves da Fontoura julgou conveniente retardar o encerramento da CMBEU, devido às repercussões negativas internas à promessa de Eisenhower de manter os compromissos passados, e ao fato de a Missão Lafer,

${ }^{11}$ Ver também EAP 53.04.27, Exame da situação econômica, realizada pela Comissão Mista Brasil - Estados Unidos, em 27/04/53. Assinatura ilegível. Balanço da cooperação financeira americana: Empréstimo US\$ 300 milhões pagáveis em três anos. Concessão de empréstimos através dos estudos da Comissão Mista Brasil - Estados Unidos pelo EXIMBANK e International Bank. Empréstimos concedidos: US\$120,350 milhões; empréstimos em fase final de negociação: US\$ 51,59 milhões; empréstimos em estudos nos bancos: US\$ 106,817 milhões; projetos ainda em elaboração no Brasil: US\$ 136,786 milhões; totalizando: US\$ 415,543 milhões. (Cruz, 1983: 100-2). 
$|170|$

O governo Vargas e a comissão mista...

de setembro de 1951, ter acertado como limite para financiamentos o valor de US\$ 500 milhões. O ministro Fontoura ia além: considerava necessário colocar a questão em termos políticos, uma vez que o Brasil era o único país na região a manter-se fiel aos EUA, e a interrupção brusca da CMBEU poderia contribuir para aumentar a campanha antinorteamericana no continente (Cruz, 1983: 105-8).

O caminho sem volta para o desmantelamento da CMBEU e, principalmente, para um fluxo de financiamentos para os projetos, no que dependia do secretário Foster Dulles, contrastava com as expectativas otimistas em torno da visita do irmão do presidente Eisenhower. Acreditava-se que com essa viagem o governo norte-americano procuraria conciliar suas diretrizes externas com alguma ação prática visando estreitar laços com a América Latina. De acordo com o embaixador britânico, "Washington feels that it has been remiss in its relations with Latin America, due to the preoccupation with the European and Asiatic crises. But once again, sentiment is beginning to reassert itself in favor of the Good Neighbor policy on a greater scale than ever". (OA 53.02.03/1)

No meio da crise que começou a se formar internamente, e às já combalidas relações bilaterais, o Secretário de Estado Foster Dulles atendeu ao pedido do governo brasileiro e concedeu mais três meses no adiamento dos trabalhos da CMBEU. Pensando na viagem de Milton Eisenhower ao Brasil em julho, os EUA facilitaram um reduzido empréstimo EXIMBANK/BIRD de US\$ 13 milhões para três projetos pendentes da CMBEU. (Weiss, 1986/2:74)

\section{O encerramento da Comissão}

Em junho de 1953 Getúlio Vargas reorganizou seu gabinete, substituindo entre outros João Neves da Fontoura e Horácio Lafer, por Vicente Rao (UDN) e Oswaldo Aranha, respectivamente, figuras mais ligadas nas negociações com os EUA. Essa reforma ministerial demonstrava insatisfação com os resultados até então obtidos pela política econômica externa. 
Vicente Rao atuava como representante na ONU desde 1950 e sua nomeação atendia aos interesses de Vargas na pasta do Exterior. Já Oswaldo Aranha era uma mudança importante na dinâmica das relações bilaterais, pois possuía uma ampla experiência no intercâmbio com o governo norte-americano. Sua entrada fortalecia a pauta econômica das conversações bilaterais, enquanto a saída de João Neves da Fontoura enfraquecia o lado político das relações. O objetivo de estreitar os laços econômicos com os EUA, todavia não foi alcançado, uma vez que a agenda econômica entre os dois países a partir de meados de 1953 restringiu-se ao debate sobre o preço-teto do café, os financiamentos para os projetos da CMBEU e ao pagamento dos atrasados comerciais. (Hirst, 1990:19)

Ao assumir a pasta em 15 de junho, Aranha de imediato avaliou os atrasados comerciais que chegavam a quase US\$ 500 milhões. A solução através de empréstimo do EXIMBANK de US\$ 300 milhões, amortizáveis trimestralmente a partir de setembro de 1953, não obtivera sucesso.

O critério utilizado pela SUMOC, após o recebimento do primeiro lote de US\$ 60 milhões, de resgate dos títulos para os quais havia sido feito cobertura em cruzeiros, não agradou aos norte-americanos. Para eles, a liquidação dos atrasados comerciais deveria obedecer a uma ordem cronológica, o que permitiria a cada entidade recolher os cruzeiros para a quitação de operações nas datas correspondentes. Como resultado, o EXIMBANK não liberou a segunda remessa de US\$ 60 milhões até que se resolvesse o impasse.

Diante desse quadro, Oswaldo Aranha propôs: 1) Resgatar o empréstimo de US\$ 300 milhões, pelo prazo de 15 anos, com início para o sexto ano, nas mesmas condições oferecidas aos argentinos; 2) desistir de novos financiamentos, com exceção dos quatro em curso (Itutinga, Central do Brasil, Salto Grande e Light), exigindo um aumento de US\$ 150 ou US\$ 200 milhões aos US\$ 300 milhões acordados; 3) encaminhar novos financiamentos à consideração do International Bank; 4) resgatar todos os atrasados comerciais, chamando a depósito em 
$|172|$

O governo Vargas e a comissão mista...

cruzeiros, de acordo com a liberação dos dólares pelo EXIMBANK; 5) acertado este programa, o BNDE daria a sua cooperação em cruzeiros aos empreendimentos industriais, transporte, eletricidade, que obtivesse no estrangeiro o crédito para a parte de suas aquisições nos vários países interessados e exportadores. (OA 53.06.19/4 e OA 53.08.04) $)^{12}$

Enquanto isso, a nova equipe do governo procurava ajustar a política financeira às exigências das agências internacionais, esperando certo abrandamento do rigor contracionista da ajuda econômica republicana aos países do continente, após a visita de Milton Eisenhower.

A intenção da viagem era mostrar aos latino-americanos que o novo governo americano se preocupava com a região e dispunha-se a melhorar as relações bilaterais. Na CMBEU, M. Eisenhower recebeu de Merwin Bohan e Ary Torres um relatório sobre os problemas estruturais e as limitações conjunturais da economia brasileira, embora se ressalvasse o aspecto não-inflacionário do programa e a capacidade da balança de pagamentos. Nesse mesmo documento se reivindicou maior cooperação dos EUA, chamando atenção ainda para o esforço de colaboração político-militar brasileiro. (OA 53.07.18)

Mais tarde, em audiência com Vargas, Rao, Aranha e Sarmanho, Eisenhower declarou implicitamente a incapacidade dos EUA para fornecer grandes empréstimos através do EXIMBANK por causa das pressões que provocariam sobre a dívida pública interna americana. Todavia propôs a Vargas tentar superar o desentendimento com o BIRD, pelo que nenhuma objeção lhe foi feita.

\footnotetext{
12 De acordo com Aranha, este programa permitiria: a) atender à defesa do cruzeiro; b) a normalização das importações dos artigos e matérias-primas essenciais; c) a concretização de nossa política de produzir petróleo (cinco anos); d) ao fomento da produção, com uma revisão automática de nossa política cambial.
} 
Da visita de Milton Eisenhower ao Brasil pouco se pôde esperar para a melhoria nas relações bilaterais, apesar de se acreditar que o presidente norte-americano se preocupava com a situação econômica da América Latina e quisesse revigorar as relações com o continente. (OA 53.02.03/1 e OA 53.08.04)

A partir de então, a CMBEU deixou de desempenhar qualquer papel no relacionamento entre os dois países. Em setembro, os EUA aceitaram ainda um pedido de prorrogação até 31 de dezembro do término da Comissão. Nos últimos meses do ano, o BIRD finalmente enviou um representante permanente para o Brasil, e concedeu US\$ 41 milhões para mais três projetos.

Nos círculos financeiros dos EUA as mudanças na política econômica efetuadas por Oswaldo Aranha causaram impacto. Em outubro de 1953, o governo anunciou um novo programa de estabilização econômica (Plano Aranha), cuja principal medida foi expressa pela Instrução 70 da SUMOC.

Pretendia-se uma modificação significativa no sistema de câmbio, substituindo o regime de licenciamento pelo da licitação das cambiais em Bolsa. As importações eram feitas pelo câmbio oficial de Cr\$18,72, mas para obter licença o importador deveria adquirir as divisas em leilões na Bolsa de Valores, pagando ágios com valores mínimos fixados segundo a essencialidade dos bens importados, agrupados em cinco categorias.

O controle das importações passou a vigorar através dos preços e o ágio mínimo variava de $\operatorname{Cr} \$ 17,00$ para a $1^{\underline{a}}$ até $\mathrm{Cr} \$ 100,00$ para a $5^{\underline{a}}$ categoria, mantendo-se com o novo sistema a proteção da indústria nacional. Embora provisório, este sistema representou uma fonte importante de receitas para o governo, elevando os custos internos de muitos produtos importados e impulsionando a substituição de importações. (OA 53.11.00/2) Significou ademais uma alteração fundamental na correlação de forças internas, uma vez que a medida privilegiou os setores industriais liderados pelos paulistas, em detrimento do setor comercial.

A iniciativa do Ministro da Fazenda teve forte impacto nos meios oficiais norte-americanos, conforme observou o 
|174|

O governo Vargas e a comissão mista...

embaixador brasileiro João Carlos Muniz: “a reação era quase de entusiasmo pelas medidas". (OA 53.08.04)

Oswaldo Aranha manteve-se crítico ao tratamento dispensado ao Brasil no caso do empréstimo de 300 milhões de dólares para quitação dos atrasados comerciais e das solicitações de financiamento aos projetos da CMBEU, ganhando o apoio dos círculos privados que se opunham ao Departamento de Estado em sua aproximação com o presidente argentino Juan Perón.

Enquanto a Argentina antes mesmo de ter dado provas concretas de mudança de atitude em relação aos EUA, recebeu US $\$ 120$ milhões, com prazos de resgate ditados segundo sua conveniência, o Brasil que se manteve cooperativo com Washington era tratado com desconfiança e descrédito.

Ao final de 1953, o desgaste nas relações entre os dois países era bastante acentuado, tendo a CMBEU encerrado oficialmente suas atividades em 21 de dezembro desse ano.

Ainda assim, a CMBEU, em acordo com o Plano de Reaparelhamento Econômico, elaborou 41 projetos individuais no total aproximado de $\mathrm{Cr} \$ 24,5$ bilhões, dos quais $\mathrm{Cr} \$ 14$ bilhões seriam financiados em cruzeiros pelos governos federal e estadual, e os outros Cr\$10,5 bilhões, equivalentes a US\$ 395 milhões (Cr\$26,25 x 1 US\$), seriam concedidos pelo BIRD ou pelo EXIMBANK (OA Brasil/USA).

Apesar de elaborados os projetos e estimados seus custos de execução, o BIRD e o EXIMBANK financiaram quinze deles no valor de US\$ 181 milhões entre 1952 e 1953. O restante ficou pendente. Segue abaixo a distribuição dos projetos quanto aos segmentos econômicos: 


\section{Projetos da CMBEU por setor econômico \\ (Em milhares de US\$ e Cr\$) \\ Custos dos projetos}

$\begin{array}{rrrr}\begin{array}{r}\text { Setor } \\ \text { Estradas de } \\ \text { Ferro }\end{array} & \text { N. de Projeto } & \text { US\$ } & \text { Cr\$ } \\ \begin{array}{r}\text { Energia } \\ \text { Elétrica }\end{array} & 17 & 150544 & 7720229 \\ \begin{array}{r}\text { Estradas de } \\ \text { Rodagem }\end{array} & 9 & 130176 & 4601011 \\ \text { Postos } & 2 & 6661 & - \\ \text { Navegação } & 4 & 37812 & 540117 \\ \text { Agricultura } & 4 & 29147 & 606325 \\ \text { Industria } & 3 & 27125 & 206000 \\ \text { Total } & 2 & 13860 & 392000\end{array}$

Fonte: CMBEU, Relatório Geral - Tomo II, 1954, quadro I.

\section{Considerações Finais}

A crise nas relações bilaterais Brasil - Estados Unidos ao final de 1953, fortalecida pelo desgaste nas negociações da CMBEU, esteve além desse episódio específico. A CMBEU foi a expressão mais imediata dessa crise. Muitas foram as insinuações dos coevos opositores de Vargas e descontentes com os resultados das relações americano-brasileiras de que a CMBEU não tinha finalidade econômica nem técnica, mas que fora sobretudo um instrumento para amainar a crise crescente nas relações entre Brasil e EUA, agravada no imediato pós-guerra. Na realidade, os desencontros e as dificuldades encontradas para o ajustamento de propostas feitas pela Comissão tanto por parte do Brasil como 
|176 |

O governo Vargas e a comissão mista...

dos EUA resultaram fundamentalmente de uma divergência de perspectivas quanto à cooperação bilateral, vale dizer:

[...] a Comissão Mista trará embutida, desde o início, um ambigüidade. Os norte-americanos tinham em mira um esforço de investimento infra-estrutural, no espírito do que estava propondo a países desenvolvidos o BIRD, ao passo que o governo Vargas pretendia tirar proveito da nova conjuntura para obter dos Estados Unidos uma ajuda mais abrangente e flexível (Furtado, 1997:266).

Em outras palavras, no âmago de negociações truncadas em torno da CMBEU repousava uma contradição central presente nas relações Brasil - EUA na primeira metade dos anos 50: a implantação de um projeto estatizante de Vargas implicava a dependência "da obtenção de recursos contingentes de uma barganha internacional em que os interlocutores controlavam a liberação de recursos exatamente para favorecer um projeto privatista" (Bastos, 2001: 477).

Nesse sentido, a rejeição do governo norte-americano às reivindicações da diplomacia brasileira pelo financiamento externo público foi uma constante nesses anos. Apenas quando a Guerra da Coréia eclodiu em 1950, e os EUA necessitavam de materiais estratégicos e apoio militar do continente, a CMBEU prevista no Ponto $I V$ de Truman começaria a tomar forma e as promessas de financiamento passariam ser efetivamente consideradas (Rabe, 1988).

Em 1952, último ano do governo Truman, o conflito coreano começara a arrefecer e o Brasil já havia dado sua contribuição antecipada no fornecimento de minerais estratégicos. Soma-se a isso a descoberta de outras reservas minerais pelo mundo. A partir desse momento, o governo americano passou a exigir que o Brasil começasse a honrar sua parcela no financiamento dos projetos elaborados pela CMBEU e que definisse políticas de controle do crescente déficit comercial externo. Além de questões geoestratégicas vinculadas mais 
diretamente ao lugar ocupado por cada país na nova ordem política e econômica internacional emergente do pós-guerra, obstáculos e dificuldades institucionais e econômicas também contribuíram decisivamente para o término da CMBEU. Nas palavras de Sérgio Besserman Vianna (1987:87-88):

De fato, as causas decisivas foram (1) a mudança de governo nos Estados Unidos; (2) a tentativa do Banco Mundial de exercer uma função tutorial sobre a política econômica dos países demandantes de crédito, assim como o conflito entre essa instituição e o EXIMBANK, com inevitáveis reflexos sobre os países da América Latina, em particular o Brasil; (3) o colapso cambial do país, que forneceu maturação e pretexto para a mudança de atitude do Banco Mundial.

Vargas e seus ministros estavam cientes da oportunidade transitória que a Guerra da Coréia oferecia para a barganha com os EUA. O Brasil deveria correr contra o tempo. Com o fim do conflito asiático em 1953, o poder de barganha brasileiro se enfraqueceu ao mesmo tempo em que na política doméstica a oposição ganhava força. O fracasso político e econômico que representou a CMBEU, embora não eliminasse as possibilidades de financiamento dos projetos de industrialização do governo Vargas, contribuiu para fragilizar ainda mais sua precária base de sustentação política.

Por outro lado, apesar de frustradas as expectativas do governo brasileiro quanto ao montante de financiamento recebido das instituições multilaterais de crédito $^{13}$, é necessário reconhecer a importância da CMBEU para a economia brasileira.

${ }^{13}$ O Banco Mundial forneceu créditos ao Brasil, entre 1951 e 1954, no valor de US\$104 milhões de dólares. No período de 1949-1954, o Brasil teria recebido dessa instituição recursos no valor de US\$ 194 milhões, dos quais, somente a Light couberam US\$ 105 milhões (Leopoldi, 1994: 168). Apesar da crescente frustração brasileira diante das perspectivas de financiamento 
|178|

O governo Vargas e a comissão mista...

Em primeiro lugar, a CMBEU, diferentemente das missões anteriores (Missão Cooke e Missão Abbink), surgiu amparada pela disposição norte-americana de financiar projetos de desenvolvimento econômico no país, ou seja, visava a resultados mais práticos na cooperação bilateral, representando "um marco na história do desenvolvimento econômico brasileiro" (Lopes, 2009: 96). Na avaliação de Pedro S. Malan (1997:62):

Em primeiro lugar, [...], a decisão de criar a comissão, nos termos referidos, constituiu uma drástica embora temporária - mudança em relação à posição oficial norte-americana desde o pós-guerra. Em segundo, porque apresentou talvez o mais abrangente diagnóstico contemporâneo sobre a economia brasileira em seu conjunto, com análises particularmente interessantes não dogmáticas sobre os problemas recorrentes de inflação e, especialmente, do desequilíbrio do balanço de pagamentos. Em terceiro lugar, porque de suas análises de projetos - e em parte da necessidade de administrar o financiamento externo esperado através de uma instituição "independente" da burocracia convencional - surgiu a idéia da criação do Banco Nacional de Desenvolvimento Econômico, que viria a desempenhar um papel fundamental que se projeta até o presente - na diversificação da estrutura industrial e na expansão da infra-estrutura produtiva da economia brasileira.

À CMBEU se estabeleceu o objetivo de elaborar projetos específicos de infra-estrutura, ligados ao setor de transporte e

externo norte-americano, os investimentos privados dos EUA no Brasil destacavam-se no mundo: entre 1949 e 1954, os investimentos líquidos daquele país no Brasil representavam 53\% do total em manufatura na América Latina e 17\% do total mundial (Vianna, 1987: 67). 
energia, para os quais se pleiteava financiamentos provenientes do BIRD e do EXIMBANK. Tais características não permitem confundi-la com o projeto de desenvolvimento nacional, voltado para a valorização global do país, integrando a questão social e a industrialização pesada (Draibe, 1985; Oliveira, 1989). Contudo, a CMBEU “[...] operou como catalisador para induzir o governo Vargas a definir, antes mesmo da posse, uma política de industrialização" (Furtado, 1997:267).

Pelo fato mesmo de o governo Vargas defender um projeto de desenvolvimento associado ao capital estrangeiro, coordenado e gerido pelo Estado, sua coexistência (representado sobretudo pela Assessoria Econômica) com a CMBEU se dava pela complementaridade de atribuições. Como assinalou Rômulo de Almeida (2004: 131), "mas havia entre os dois segmentos da administração econômica de Vargas um certo entendimento, não havia conflito". Certamente a CMBEU muito contribuiu para o planejamento econômico brasileiro, deixando um legado técnico e institucional que perdura no tempo. Contudo, seu encerramento além de evidenciar uma situação de crise nas relações entre Brasil e EUA, explicitou o caráter assimétrico das conversações entre ambos, e a postura unilateral do regionalismo norte-americano para a América Latina do pós-guerra.

\section{Bibliografia}

ALMEIDA, Rômulo de. A política econômica do segundo governo Vargas. In: Getúlio Vargas e a economia contemporânea. 2.․․ ed. Campinas: Editora da Unicamp. 2004

BASTOS, Pedro P. Z. A dependência em progresso: fragilidade financeira, vulnerabilidade comercial e crises cambiais no Brasil (1890-1954). Tese (doutorado), Universidade Estadual de Campinas. 2001

BIELSCHOWSKY, Ricardo. 1996. Pensamento econômico brasileiro: o ciclo ideológico do desenvolvimentismo. $3 .{ }^{a}$ ed. Rio de Janeiro: Contraponto. 1996 
O governo Vargas e a comissão mista...

CAMPOS, Roberto de Oliveira. A Lanterna na popa: memórias. Rio de Janeiro: Topbooks.

COHN, Gabriel. 1968. Petróleo e nacionalismo. São Paulo: Difel. 1994

CRUZ, Adelina M. A. Novaes. et. al. (Org.). Impasse na democracia brasileira, 1951-1955: textos e documentos. Rio de Janeiro: FGV. 1983

D'ARAÚJO, Maria Celina. O segundo governo Vargas (1951-1954): democracia, partidos e crise política. 2.․ ed. São Paulo: Ática. 1992

DRAIBE, Sonia. Rumos e metamorfoses: Estado e industrialização no Brasil (1930/1960). Rio de Janeiro: Paz e Terra, 1985.

FURTADO, Celso. A Fantasia Organizada (Obra Autobiográfica). São Paulo: Paz e Terra. 1997

GV. Arquivo Getúlio Vargas. Centro de Pesquisa e Documentação de História Contemporânea do Brasil - CPDOC/FGV.

HILTON, Stanley E. "The United States, Brazil, and the Cold War, 1945-1960: End of the Special Relationship". The Journal of American History, v. 68, n.․ 3, Dec., p. 599-624. 1981

HIRST, Mônica. O pragmatismo impossível: a política externa do segundo governo Vargas (1951-1954). Rio de Janeiro: CPDOC/ FGV. 1990

IANNI, Octavio. Estado e planejamento econômico no Brasil (1930-1970). Rio de Janeiro: Civilização Brasileira. 1971

LEOPOLDI, Maria A. P. O difícil caminho do meio: Estado, burguesia e industrialização no segundo governo Vargas (1951-54). In GOMES, Ângela de C. (Org.). Vargas e a crise dos anos 50. Rio de Janeiro: Relume-Dumará. 1994

LOPES, Márcio Augusto F. O fracasso da Comissão Mista Brasil Estados Unidos e os rumos da política econômica no segundo governo Vargas (1951-1954). Dissertação de Mestrado em Economia Política, PUC/SP. 2009

MALAN, Pedro Sampaio. et. al. Política econômica externa e industrialização no Brasil (1939/1952). Rio de Janeiro: IPEA/INPES. 1997 
OA. Arquivo Oswaldo Aranha. Centro de Pesquisa e Documentação de História Contemporânea do Brasil - CPDOC/FGV.

OLIVEIRA, Francisco de. A economia da dependência imperfeita. 5. ed. Rio de Janeiro: Graal. 1989

RABE, Stephen G. Eisenhower and Latin American: the foreign policy of Anti-communism. University of North Carolina Press. 1988

SZMRECSÁNYI, Tamás e GRANZIERA, Rui G. (Org.). Getúlio Vargas e a economia contemporânea. 2.․ ed. Campinas: Editora da Unicamp. 2004

VARGAS, Getúlio. O Governo Trabalhista no Brasil. Vol. II. Rio de Janeiro: Livraria José Olympio. 1954

. O Governo Trabalhista do Brasil. Vol. III. Rio de Janeiro: Livraria José Olympio. 1969

VIANA, Márcia Maria D'Avila. A Comissão Mista Brasil - Estados Unidos no contexto do II Vargas. Dissertação de mestrado em Economia, Unb. 1980

VIANNA, Sérgio Besserma. A política econômica do segundo governo Vargas $(1951$ - 1954). Rio de Janeiro: BNDES. 1987

. Duas tentativas de estabilização: 1951-1954. In ABREU, M. de P. (Org.) A Ordem do Progresso - Cem anos de Política Econômica Republicana 1889 - 1989. Rio de Janeiro: Campus. 1989

WEISS, Michael. "A Comissão Mista Brasil - Estados Unidos e o mito da 'relação especial'". Revista Brasileira de Política Internacional. Rio de Janeiro, IBRI, v. 29, n.o 115-116. 1986 